\title{
Remaining lifetime modelling of power transformers on individual and population level
}

\section{Citation for published version (APA):}

Wouters, P. A. A. F., Schijndel, van, A., \& Wetzer, J. M. (2010). Remaining lifetime modelling of power transformers on individual and population level. In Proceedings of the IEEE 10th International conference on Solid Dielectrics, Potsdam Germany, 04-09 July 2010 (pp. 577-580). Institute of Electrical and Electronics Engineers. https://doi.org/10.1109//CSD.2010.5568112

DOI:

10.1109/ICSD.2010.5568112

Document status and date:

Published: 01/01/2010

\section{Document Version:}

Publisher's PDF, also known as Version of Record (includes final page, issue and volume numbers)

\section{Please check the document version of this publication:}

- A submitted manuscript is the version of the article upon submission and before peer-review. There can be important differences between the submitted version and the official published version of record. People interested in the research are advised to contact the author for the final version of the publication, or visit the $\mathrm{DOI}$ to the publisher's website.

- The final author version and the galley proof are versions of the publication after peer review.

- The final published version features the final layout of the paper including the volume, issue and page numbers.

Link to publication

\section{General rights}

Copyright and moral rights for the publications made accessible in the public portal are retained by the authors and/or other copyright owners and it is a condition of accessing publications that users recognise and abide by the legal requirements associated with these rights.

- Users may download and print one copy of any publication from the public portal for the purpose of private study or research.

- You may not further distribute the material or use it for any profit-making activity or commercial gain

- You may freely distribute the URL identifying the publication in the public portal.

If the publication is distributed under the terms of Article 25fa of the Dutch Copyright Act, indicated by the "Taverne" license above, please follow below link for the End User Agreement:

www.tue.nl/taverne

Take down policy

If you believe that this document breaches copyright please contact us at:

openaccess@tue.nl

providing details and we will investigate your claim. 


\section{Remaining Lifetime Modelling of Power Transformers on Individual and Population Level}

\author{
Peter Wouters, Arjan van Schijndel \\ Faculty of Electrical Engineering, EES group \\ Eindhoven University of Technology \\ P.O. Box 513, 5600 MB Eindhoven, the Netherlands \\ p.a.a.f.wouters@tue.nl
}

\author{
Jos Wetzer \\ KEMA Nederland B.V. \\ P.O. Box 9035, 6800 ET Arnhem, the Netherlands \\ jos.wetzer@,kema.com
}

\begin{abstract}
The age of the majority of power transformers installed in the western electricity network reaches 30 to 60 years and replacement on short term seems eminent. A technically sound policy concerning the replacement of these assets requires a model that estimates the life expectancies of individual components and from that calculates parameters related to the behavior of a population of assets as a whole. We will illustrate the approach by applying it to a well-known degradation process: thermal degradation of the transformer paper insulation. In this paper we focus on the determination of the population reliability from individual reliabilities. These individual reliabilities are based on Arrhenius modelling of paper insulation degradation including its inherent uncertainties. A statistical failure model is used to obtain the population reliability figures. We demonstrate the modelling method by applying it to an existing population of power transformers in the Netherlands, to evaluate the expected replacement wave. Further, the model is applied to analyse alternative replacement scenarios.
\end{abstract}

Keywords-paper insulation, power transformer insulation, reliability estimation.

\section{INTRODUCTION}

In the current western electricity network the majority of the components are installed between 1950 and 1980, the ages thereby varying between 30 and 60 years. Replacement on short term seems to be imminent and utilities are confronted with the following questions:

- What is the life expectancy or reliability of individual components?

- How do failure probabilities cumulate to a replacement wave?

- (How) can the expected replacement wave be managed?

Proper maintenance and proactive grid upgrade increases the expected remaining life of individual transformers, and as a consequence the reliability of the population as a whole. The individual reliabilities allow selecting the most endangered assets, and load, maintenance and replacement policy can be adjusted and fine tuned. The effectiveness of the measures taken can be extracted from the population probabilities.

We employ a predictive model which involves three essential ingredients: reliability engineering, physical understanding of the degradation process, and actual knowledge of the present condition [1]. The model is applied to the degradation of the transformer winding insulation [2]-[7]. In earlier work a modeling approach for a transformer population was presented based on the mechanical strength of the paper insulation [8]-[9].

\section{MODELING TRANSFORMER RELIABILITY}

The decline in the DP value (Degree of Polymerization) is a result of a cascaded chemical reaction resulting in the scission of the cellulose chains. A simplified temperature dependency model of the DP-value is given by the Arrhenius relation, as is extensively discussed in [2]-[5]. This has lead to the following relation:

$$
\frac{1}{D P(t)}-\frac{1}{D P(0)}=\int_{0}^{t} k(\tau) d \tau,
$$

where $D P(t)$ is the DP-value at time $t, D P(0)$ is the initial DP value and $k(t)$ is the time dependent reaction rate. The time dependant reaction rate has the Arrhenius form

$$
k=A \exp \left(-\frac{E_{a}}{R_{g} T}\right),
$$

where $E_{a}$ is the molar activation energy, $R_{g}$ the universal gas constant, $A$ a process constant and $T$ the absolute temperature (see Table I). For the $T$, the hotspot-value of the IEC (International Electrotechnical Commission) loading guide [6] is used. The steady state hotspot-temperature is

$$
\theta_{h}=\theta_{a}+\Delta \theta_{o r}\left(\frac{1+R I^{2}}{1+R}\right)^{x}+\theta_{h r} I^{y},
$$

where $I$ is the time dependent relative load per unit. The other input parameters are: oil exponent $x$; winding exponent $y$; loss ratio $R$; ambient temperature $\theta_{a}$; Hot-spot to top-oil gradient $\theta_{h r}$; and top-of-tank oil rise $\Delta \theta_{o r}$. The reliability is obtained by integration of all DP-values, indicated with $v$, according to

$$
R_{i}(t)=1-\int P_{t h}(v) p_{d p}(v, t) d v .
$$

Here $p_{d p}$ is the distribution function of the DP-value and $P_{t h}$ the probability that the transformer has failed with a specific DPvalue. In this case we use truncated normal distributions with mean $\mu$ equal to the DP-value on time $t$ and $\sigma$ equal to uncertainty value. For the DP-threshold paper insulation has a critical condition around a DP value of 250. An uncertainty of $10 \%$ in this value is assumed.

The research presented is made possible by the financial support and active participation of KEMA Nederland B.V., Enexis B.V. and Stedin B.V. 
TABLE I. DATA TO CALCULATE THE MEAN-RESIDUAL-LIFE OF KRAFT AND THERMALLY UPGRADED PAPER, ACCORDING TO [2] AND [4]

\begin{tabular}{ccccc}
\hline Winding insulation paper & $\boldsymbol{A}\left(\mathbf{h o u r}^{-1}\right)$ & $\boldsymbol{E}_{\boldsymbol{a}}(\mathbf{k J} / \mathbf{m o l})$ & $\boldsymbol{D P}_{\text {initial }}$ \\
\hline \multirow{2}{*}{ Kraft } & Emsley & $1.07 \cdot 10^{8}$ & & \\
& Lundgaard & $2.0 \cdot 10^{8}$ & \multirow{2}{*}{111} & 1000 \\
\cline { 1 - 2 } Thermally & Emsley & $0.37 \cdot 10^{8}$ & & \\
upgraded & Lundgaard & $0.67 \cdot 10^{8}$ & & \\
\hline
\end{tabular}

The individual reliability results can be used to obtain the reliability of a transformer population. The method assumes that the individual reliabilities $R_{i}$ are uncorrelated. The probability that at least $i$ out of a set of $j$ transformers are operational is equal to the probability that the "last" transformer $j$ has failed and from the remaining $j-1$ at least $i$ transformers work, plus the probability that transformer $j$ is in working order and a maximum of $i-1$ of the rest are working.

$$
R^{(i, j)}=\left(1-R_{j}\right) \cdot R^{(i, j-1)}+R_{j} \cdot R^{(i-1, j-1)}
$$

The superscript $(i, j)$ indicates that at least $i$ out of $j$ transformers are still operational. The begin and end condition of $(5)$ are $R^{(0, j)}=1$ and $R^{(j+1, j)}=0$. This algorithm reduces the analysis for a system of up-to $k$ failures from a population of $N$ transformers to the order of $N \times k$ operations [8],[10]. Moreover, the results for up to $k-1, k-2$, etc. are directly available as intermediate result of the recurrent analysis. From (5) the mean-time-to-failure (MTTF) of the failure of less than $k$ transformers, $M T T F_{k}$, can be written as

$$
\operatorname{MTTF}_{k}=\int_{0}^{\infty} R^{(N-k+1, N)}(t) d t .
$$

Equation (6) links the time with the population reliability. The population reliability $R_{P}$ belonging to the $M T T F_{k}$ is defined as

$$
R_{P}\left(t=M T T F_{k}\right)=\frac{N-k}{k} .
$$

\section{TRANSFORMER FLEET EXAMPLE}

The installation dates of the combined population of two utilities consisting of 579 distribution transformers are depicted in Fig. 1. The model is applied to investigate whether utilities have to be prepared for a failure wave of power transformers in the near future. The IEC transformer design guide [11] assumes a life span of 40 years under nominal loading conditions. If this would be the case, a failure wave could be expected between 2010 and 2020 assuming all transformers are nominally loaded. In order to make precise predictions the actual loads and load cycles of individual transformers must be incorporated. Further, the load is expected to gradually increase in the future.

As failure mechanism the paper degradation model discussed in Section II is taken for each individual transformer. Many transformers lack precise historical data and assumptions have to be made. For the modeling parameters, the following conditions are taken:

- installation date and cooling method is available from the database;

- ambient temperature is taken according to average values;

- historical load pattern is used and a regular increase in load is assumed;

- the accuracy of all input parameters are taken $5 \%$ of their actual value, except for the load which is taken $10 \%$;

- all transformers are located outside, and cooled by wind;

- transformers are continuously in operation.

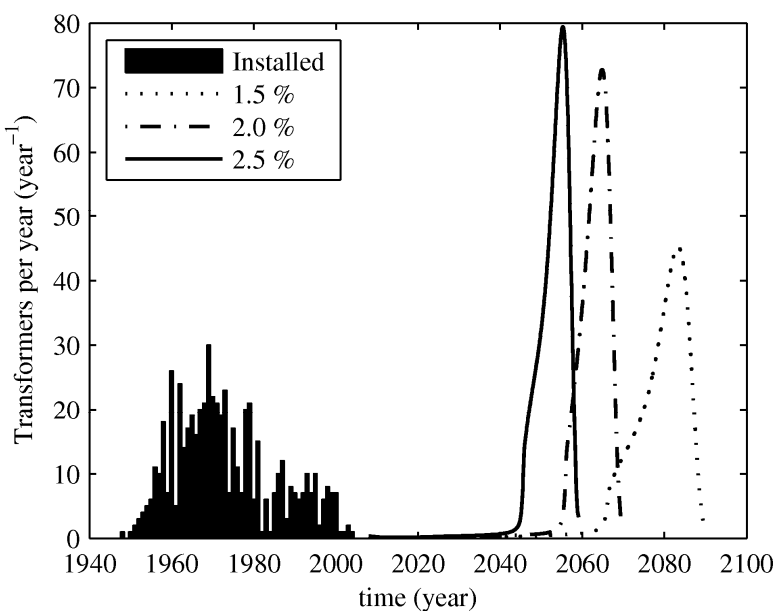

Figure 1. Transformer installation dates for 579 transformers (bars) together with expected failure waves for load growth of $1.5 \%, 2 \%, 2.5 \%$

The year of installation and the cooling modes are extracted from the combined population databases. From these populations, next to the installation time, the cooling modes: Oil-Natural-Air-Natural (ONAN), Oil-Natural- Air-Forced (ONAF), Oil-Forced (OF) and Oil-Directed (OD) are used as input parameters. The transformer parameters belonging to the cooling modes are derived from the current IEC loading guide [6]. For the ambient temperature, $\theta_{a}$, the temperature model of the IEC loading-guide [12] is used:

$\theta_{a}(t)=\theta_{a y}+A_{1} \cos \left[\frac{2 \pi}{24 \cdot 365}\left(t-24 \varphi_{1}\right)\right]+A_{2} \cos \left[\frac{2 \pi}{24}\left(t-\varphi_{2}\right)\right](8)$

with time $t$ in hours. The constants in (10) are $\theta_{a y}=9.4^{\circ} \mathrm{C}$, $A_{1}=7.4{ }^{\circ} \mathrm{C}, \varphi_{1}=199$ days, $A_{2}=13{ }^{\circ} \mathrm{C}$ and $\varphi_{2}=15$ hours based on historical outside temperature averages. The current yearly load growth is about $2 \%$. To obtain the per-unit load the average for every hour in the period 2003-2006 is calculated. This average is taken for the (reference) year 2008 and every hourly value is then normalized such that the maximum hourly value occurring throughout a year corresponds to a per-unit load of 0.4 .

One of the critical assumptions is the annual load growth. As a reference a value of $2 \%$ is chosen. In order to determine the sensitivity of the failure wave with respect to the load growth, this parameter is varied. The results are plotted in Fig. 1. A $2 \%$ load growth results in a failure peak in the year 2063. A $0.5 \%$ lower or higher value shifts the peak 10 years forward or 15 years backwards, respectively. Furthermore, the peak narrows. This is related to accelerated ageing, when the rated transformer power is approached. This occurs for every transformer at the same moment, since they all are assumed to have equal load in the reference year.

\section{REPLACEMENT Alternatives}

The transformer population model not only aims to predict future failure rates, but also to analyze the effectiveness of maintenance/replacement strategies. Two case studies are given. The first example studies the effect of a few hypothetical replacement approaches on the distribution transformer population discussed in Section III. The second example investigates the effects on a small population of transformers from which the load history is available. 


\section{A. Transformer Fleet Example}

This simplified alternative addresses a mitigation action, where any endangered transformer gets assistance in the form of load sharing with a new additional transformer. As an example, annually six transformers are added to the existing assets to relieve transformers that are expected to be aged considerably. The selection process takes place over a period of 40 years starting in 2009. An initial load of 0.4 p.u. and an annual load growth of $2 \%$ is assumed. In the transformer failure distribution of Fig. 2 it is seen that the replacement alternative (solid line) results in a reduction and a slight shift of the original replacement probability (dotted line). There is no preference in the order where to install the first new transformers. This is related to the equal load assumption taken for all transformers. No efficient selection can be made of transformers to be replaced. Only by actually measuring the DP values a transformer selection scheme is possible. If not, the number of transformers to be added yearly must be of the order of the total number of transformers involved divided by the expected duration up to the expected replacement peak, i.e. about thirteen transformers per year (dash-dotted line in Fig. 2).

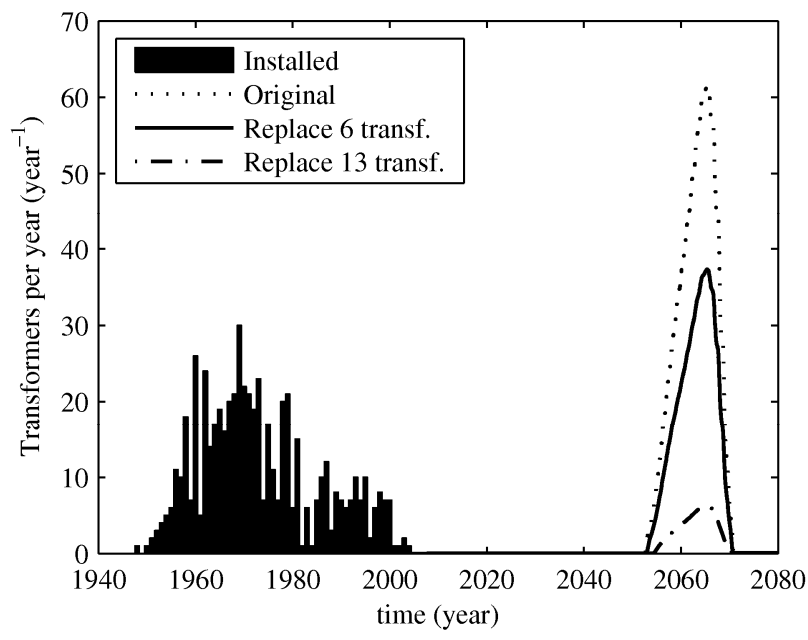

Figure 2. The replacement wave with a $2 \%$ annual load growth without measure (dotted line), and with annually upgrading six transformers (solid line) or thirteen transformers (dash-dotted line).

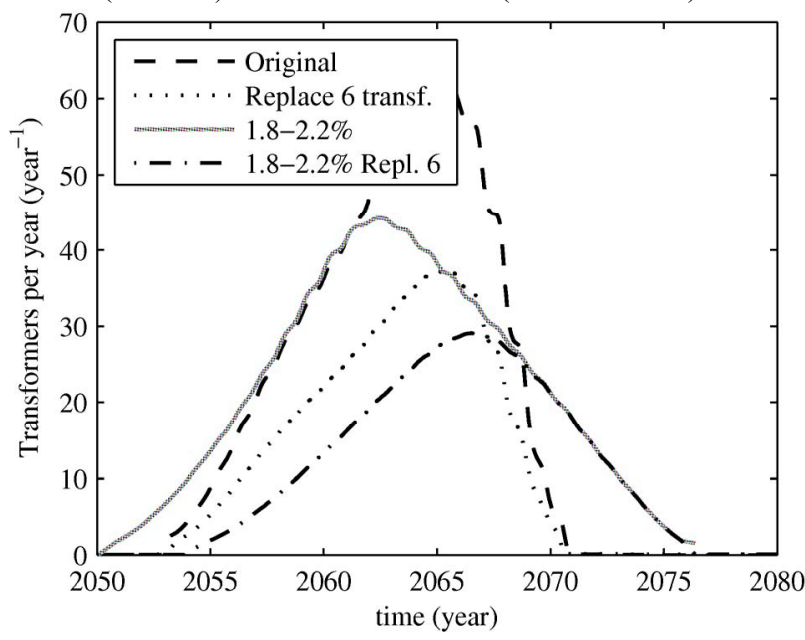

Figure 3. The replacement wave with a fixed $2 \%$ annual load growth without and with annually upgrading six transformers, and replacement waves including a variation of annual load between 1.8 to $2.2 \%$.
The load of transformers depend on the region they are situated and on the type of users which are connected. The "equal load" assumption is only achieved when transformers would be permutated between substations with relatively large and low load. In this example, the load growth percentage is varied to enforce diversity in the individual loading scenarios. Five groups of different load growth percentages are formed with an almost equal number of transformers. The load growth percentages are between $1.8 \%$ and $2.2 \%$ with steps of $0.1 \%$. All other assumptions are kept the same. Further, annually six most aged transformers get load sharing, which reduce their load by a factor two. The results are plotted in Fig. 3. The following observations can be made:

- As compared to the fixed 2\% load growth simulation for all transformers (dashed line), the distributed growth rate (solid line) causes a broadening in Fig. 3 and a drop of the peak from 60 to 40 transformers per year. Transformers with high load growth tend to fail earlier and transformers with a relative low growth in load later, implying a broadened distribution.

- If the policy of six added transformers is applied again a broader distribution is obtained for the 1.8-2.2\% load growth situation (dash-dotted line) as compared to the equal growth (dotted line). However, the peak is completely shifted, indicating that now transformers can effectively be selected.

- With distributed load growth, the replacement strategy of annually six transformers is far more efficient than in an equal load situation.

\section{B. Three Substation Example}

The load of every individual transformer from three Dutch substations, each with three transformers, has been logged every five minutes in the year 2008 and their monthly maximum load values are logged over twelve years. The load values are used to determine the annual load growth percentage by linear fitting resulting in an average of about $1 \%$ yearly load growth for the 1996-2008 period. The 2008 individual transformer load is extrapolated for the remaining years with a load growth of $1 \%$.

The transformer data are extracted from the manufacturer's test reports. The dynamical temperature model is taken from [6],[13]. The degradation parameters of the applied Kraft-paper are taken from Table 1 (Kraft, [4]). The ambient temperature of all transformers is assumed to follow the temperature model of the former IEC loading-guide [12] as expressed in (8).

Each substation contains two busbars with a connected transformer. The third transformer is only connected when one of the others is in maintenance. Since the busbars have unequal load and the spare transformer is only occasionally in operation, the expected remaining transformer lifetimes differ. These individual lifetimes are calculated and combined to a population reliability distribution. This distribution and its reliability density function are plotted in Fig. 4 (solid lines). An equally shared load over all transformers in each substation is expected to result in a more efficient usage of the assets. To this end, the present loading strategy is compared to a shared load. Consider a hypothetical situation, where as from 2009 the two active transformers share equally the load of both busbars. Further, a rotating scheme is adopted for the third transformer 
such that over longer time all transformers are equally loaded. The result of this equal load scenario (dotted lines) is a steeper decline of the reliability and a delay of the first failure. The expected time of first failure is delayed by ten years and all transformers are expected to fail in half of the time.

\section{DISCUSSION AND CONCLUSION}

From the annual replacement strategies of Section IV-A it can be observed that the equal load is most unfavorable since there is no preference in the order of replacement, except for the installation date. The installation date however may hardly be reflected in the end of life distribution. Further, it can be seen that for a preventive replacement of all transformers, the transformers need to be replaced before the beginning of the failure wave. A variation in load growth percentage between transformers leads to a spread of the replacement wave. As further optimization one could consider having a dynamic replacement strategy starting with less replacements per year, but after some time this value is increased. Failure of transformers in the three substations of Section IV-B could be delayed by a rotating scheme, such they share more or less equal load. The negative effect is that the transformers will fail in a shorter period of time.
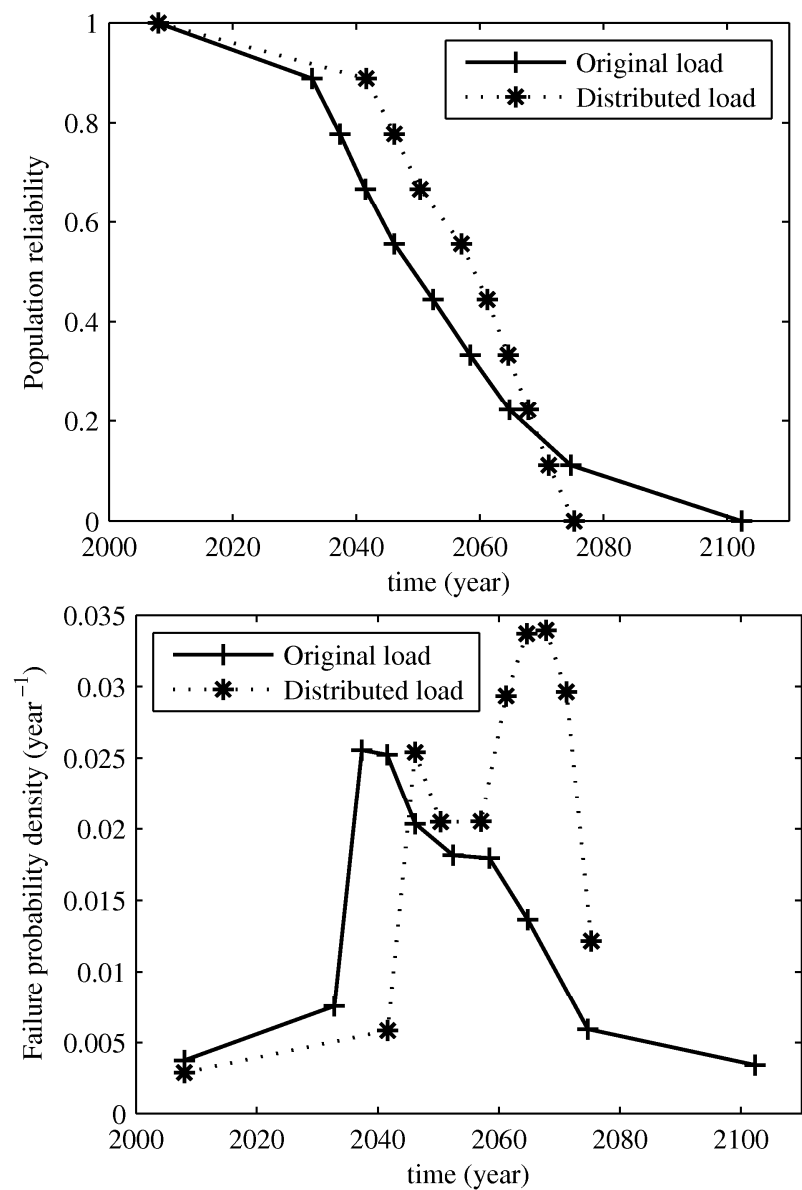

Figure 4. The fleet reliability (top) and probability density function (bottom) of nine transformers in three substations: the solid line represents the original load situation; the dotted line represents the reliability of the substation, with two transformers equally loaded and using a rotation scheme.
Apparently, it is more favorable to have transformers with a significant loss of life before adding an extra transformer than trying to get an equal load as much as possible. Judgment of these strategies not only involves a technical reliability model, but requires a complete asset management approach of which the technical model is a small, but crucial, part. The strategy of spreading the expected replacement wave over a manageable time period faces a difficult selection mechanism, depending heavily on correct information. The information needed for selecting the right set of transformers to be replaced are historical load, historical fault and failure situations, future load scenarios, future stresses, and maintenance schemes to mitigate secondary failures. The benefit of this strategy is that it is relatively easy to manage. The obvious downside is the fact that the components are not used for their maximum operational life. However, depending on replacement policy, the maximum utilization by having equal loads for all assets is not necessarily the best strategy economically.

\section{ACKNOWLEDGMENT}

We gratefully acknowledge the contributions of Harry Verhaart, Maarten Berende and Herman Arts.

\section{REFERENCES}

[1] A. van Schijndel, J. M. Wetzer, and P. A. A. F. Wouters, "Forecasting transformer reliability," 2006 IEEE Conf. Electr. Insul. Dielectr. Phenom. (CDEIP), pp.577-582, Oct. 2006.

[2] A. M. Emsley and G. C. Stevens, "Review of chemical indicators of degradation of cellulosic electrical paper insulation in oil-filled transformers," IEE Proc. Sci. Meas. Technol., Vol.141, no.5, pp.324334, Sep. 1994.

[3] A. M. Emsley, R. J. Heywood, M. Ali, and X. Xiao, "Degradation of cellulosic insulation in power transformers. Part 4: Effects of ageing on the tensile strength of paper," IEE Proc. Sci. Meas. Technol., Vol.147, No.6, pp.285-290, Nov. 2000

[4] L. E. Lundgaard, W. Hansen, D. Linhjell, and T. J. Painter, "Aging of oil-impregnated paper in power transformers," IEEE Trans. Power Del., Vol.19, No.1, pp.230-239, Jan. 2004.

[5] Cigré 323, "Ageing of cellulose in mineral-oil insulated transformers," Cigré Report, 2007.

[6] IEC, "Power transformers - Part 7: Loading guide for oil-immersed power transformers," IEC 60076-7, Dec. 2005.

[7] IEEE, "IEEE guide for loading mineral-oil-immersed transformers," IEEE C57.91-1995, Apr. 1996.

[8] Arjan van Schijndel, Jos M. Wetzer, and Peter A.A.F. Wouters, "Modelling technique for power transformer replacement waves," $10^{\text {th }}$ Int. Conf. Prob. Meth. Appl. Power Syst. (PMAPS), paper 10, May 2008.

[9] A. van Schijndel, J. M. Wetzer, and P.A.A.F. Wouters, "Forecasting reliability of transformer populations," $19^{\text {th }}$ Int. Conf. Electr. Distr. (CIRED), paper 108, May 2007.

[10] W. Kuo and M. J. Zou, Optimal reliability modeling, Hoboken, New Jersey, USA: John Wiley \& Sons, Inc., 2003.

[11] IEC, "Power transformers - Part 14: Design and application of liquidimmersed power transformers using high-temperature insulation materials," IEC 60076-14, 2.0 edition, May 2009.

[12] IEC, "Loading guide for oil-immersed power transformers," IEC 60354, Oct. 1991.

[13] H. Nordman, N. Rafsback, and D. Susa, "Temperature responses to step changes in the load current of power transformers," IEEE Trans. Power Del., Vol.18, No.4, pp.1110-1117, Oct. 2003. 